we have conducted a number of studies on the selenium content of teeth, placental tissue, and foetal cord blood, bovine milk, eggs, water, and human milk in relation to dental caries susceptibility in children. ${ }^{5-9}$

There is no doubt that the role played by trace elements in preventing dental caries requires further exploration. It is believed, however, that the study of trace elements that may be responsible for increasing the susceptibility to dental caries, such as selenium, should also be given serious consideration by research workers.-I am, etc.,

University of Oregon Dental School

\section{M. Hadjimarkos.}

\section{REFERENCES}

1 Tank, G., and Storvick, C. A., J. dent. Res., 1960, 39, 473.

Hadjimarkos, D. M., Storvick, C. A., and Remmert, L. F., J. Pediat., 1952, 40, 451

3 and Bonhorst, C. W., ibid., 1958, 52, 247.

- Büttner, W., J. dent. Res., 1963, 42, 453 (Supp.)

- Hadjimarkos, D. M., and Bonhorst, C. W., Oral Surg., 1959,

- 12, 113. and Mattice, J. J., J. Pediat., 1959, 54, 296

二- ibid., 1961, 59, 256 .

- Nature (Lond.), 1962, 193, 177

- J. Pediat., in press.

\section{Ettriol Trinitrate and Prenylamine Lactate in Angina Pectoris}

SiR,-An effective method for the prolonged relief of severe angina pectoris is badly needed. Glyceryl trinitrate (trinitrin) relieves angina rapidly but its action is short-lived. And none of the many drugs claimed to produce prolonged relief have proved active when tested by acceptable methods of double-blind trial. The most widely prescribed, pentaerythritol tetranitrate, showed no effect even in doses of $180 \mathrm{mg}$. daily ${ }^{1}$; and the various monoamine oxidase inhibitors have proved no better, as well as causing deaths from liver damage. The search continues, and I wish to report briefly doubleblind trials of two recent drugs, claimed to be effective for the prolonged control of angina.

1. Ettriol trinitrate (E.T.T.N.) in experimental animals has shown actions on smooth muscle and coronary blood-flow similar to trinitrin. Sowton and Oram $^{2}$ found E.T.T.N. to be as effective as trinitrin for the rapid relief of anginal pain. Prolonged improvement of angina has been reported, though a controlled trial did not confirm this improvement. ${ }^{3}$ Twelve patients with typical severe angina took part in a double-blind trial; E.T.T.N. $10 \mathrm{mg}$. three times daily was given during the treatment period. Two patients improved on E.T.T.N., with more angina in the control period. The trial periods were repeated in both patients, when there was no difference between the E.T.T.N. and placebo periods. One patient improved during the control period, with more pain on E.T.T.N. Three patients showed moderate improvement in both periods, and four noticed no change in angina throughout the trial.

2. Prenylamine lactate increases coronary blood flow in animals, and the only double-blind trial ${ }^{4}$ showed moderate improvement with prenylamine in four out of six patients. Eleven patients, with severe angina, took part in a doubleblind trial, receiving prenylamine in a dose of $30 \mathrm{mg}$. three times daily. Three patients showed slight improvement during the prenylamine period only, and two during the control period only. Three showed improvement throughout both periods of the trial, and in three angina persisted unchanged.

Neither ettriol trinitrate nor prenylamine lactate have proved more effective than control tablets for the prolonged relief of angina, when tested by a doubleblind technique. Only one drug, trinitrin, is accepted as valuable for the relief of angina. The mechanism of

its action is uncertain. In normal subjects trinitrin causes coronary vasodilatation; but in patients with angina there is no increase in coronary blood-flow and occasionally even a decreased flow. Cardiac work is invariably decreased, owing to a fall in blood-pressure from peripheral vasodilatation, and this decrease in cardiac work may relieve angina. The coronary response suggests maximal dilatation of the coronary tree and collateral vessels even in the resting state, with no increase of coronary blood flow possible after trinitrin or exercise. ${ }^{5}$ It is doubtful whether the coronary arteries can be dilated by any drug more effectively than by the potent vasodilator stimulus of surrounding tissue ischaemia. And if coronary blood-flow does not increase with trinitrin, other coronary vasodilators with a more gentle and prolonged action are unlikely to dilate atherosclerotic coronary arteries.

Frequent disappointments in the past indicate that the spate of new drugs introduced for angina require formal testing before acceptance. At present we have no drug of proved value. Angina frequently improves with prolonged anticoagulant treatment, ${ }^{6}$ perhaps by prevention of recurrent small thromboses or by encouragement of collateral circulation; and the high incidence of infarction in these patients is considerably reduced by anticoagulants. ${ }^{7} \quad$ Treatment of severe angina must therefore at present depend on general measures such as weight loss, reduction of smoking, and sedation; correction of precipitating factors such as anaemia, hypertension, or myxoedema; and anticoagulants if symptoms warrant. Fortunately, at least half these patients will improve with interest and enthusiasm alone. -I am, etc.,

$$
\text { Welwyn Garden City, }
$$

Hertfordshire.

David N. Phear.

\title{
REFERENCES
}

1 Phear, D., and Walker, W. C., Brit. med. J., 1960, 2, 995.

2 Sowton, E., and Oram, S., ibid.,., 1961, 1. 794.

3 Oram, S., and Sowton, E., ibid., 1961, 2, 1745.

4 Baumgarten, A., Med. J. A ust., 1962, 49, 429.

"Gorlin, R., Brachfeld, N., MacLeod, C., and Bopp, P., Circulation $1959,19,705$.

Parry, E. H. O., and Wells, P. G., Brit. med. J., 1960, 1, 26.

Borchgrevink, C. F., Acta med. scand., 1960, 168, Suppl. 359.

\section{Eaton Agent}

SIR,- - The author of your interesting leading article on "Respiratory Illness caused by Mycoplasma " (May 11, p. 1246) appears to have overlooked the recent work of Dr. Phyllis Pease. ${ }^{1}$ She has produced convincing evidence that the Eaton agent is an $\mathrm{L}$ form of streptococcus MG, an observation which may prove to be of great biological importance.-I am, etc.,

Birmingham 15.

1 Pease, P., Nature (Lond.),

\section{Detection of Glaucoma}

SIR,-In his letter Mr. R. A. Greeves (May 4, p. 1231) suggests that tonometric measurements on all persons over 40 are not practicable. I thought, therefore, that your readers might like to know that Drs. Mackay and Marg (of the School of Optometry, Berkeley, California) have developed a guard-ring electromanometer, $3 \mathrm{~mm}$. in diameter, which gives an accurate recording of the pressure in the anterior chamber if touched against the eyeball for two seconds. No local anaesthetic is necessary. The contact area of the instrument is smooth and covered with a sterile rubber membrane, and its application to the eyeball is not uncomfortable. It is 